\title{
O Pronaf como estratégia de desenvolvimento rural: o acesso aos recursos no estado de Santa Catarina
}

Juliano Luiz, Fossá*

Resumo: O trabalho apresentado tem por objetivo discutir a distribuição e acesso aos recursos financeiros do Pronaf no estado de Santa Catarina. Inicialmente realizou-se uma revisão da literatura em relação ao desenvolvimento a partir da uma concepção de Celso Furtado, na sequência, ainda quanto ao referencial teórico foram apresentados aportes iniciais sobre desenvolvimento rural, agricultura familiar e sobre o Pronaf. Os resultados apontam que o volume de recursos no período de 1996 a 2016 cresceu o equivalente a 5,5 vezes, em contrapartida o número de contratos não apresentou oscilações consideráveis, permanecendo praticamente constante. Os valores médios dos contratos apresentaram significativos aumentos tanto na linha de custeio como para a linha de investimento. Constata-se que praticamente $60 \%$ dos recursos contratados no período em análise foram acessados por agricultores pertencentes à região Oeste, concentração que ressalta a significativa presença da agricultura familiar na região bem como seu estágio de desenvolvimento frente às demais regiões do estado. É possível concluir que o Pronaf consiste de importante política pública de apoio ao segmento familiar rural do estado de Santa Catarina, ao mesmo tempo em que aponta para o crescimento da necessidade de recursos financeiros para a viabilização das atividades produtivas.

Palavras-chave: desenvolvimento rural; agricultura familiar; Pronaf.

\section{The Pronaf as a strategy for rural development: access to resources in the state of Santa Catarina}

\begin{abstract}
This paper aims to discuss the distribution and access to financial resources of Pronaf in the state of Santa Catarina. At first a literature review was carried out based on a Celso Furtado conception, and then, as for the theoretical reference, initial contributions were presented on rural development, family farming and on Pronaf. The results indicate that the amount of resources in the period from 1996 to 2016 increased the equivalent of 5.5 times, in contrast the number of contracts did not show considerable oscillations, remaining practically constant. The average values of the contracts showed significant increases in both the cost line and the investment line. It is observed that almost $60 \%$ of the resources contracted in the period under analysis were accessed by farmers belonging to the West region, a concentration that highlights the significant presence of family farming in the region as well as its stage of development compared to other regions of the state. It is possible to conclude that Pronaf consists of an important public policy to support the family farming segment of the state of Santa Catarina, at the same time as it points to the growth of the need of financial resources for the viabilization of productive activities.
\end{abstract}

Keywords: rural development; family farming; Pronaf.

JEL: Q10, Q18

\footnotetext{
* Professor da Universidade Regional de Chapecó (UNOCHAPECÓ) e doutorando em Administração no Programa de Pós Graduação em Administração da Universidade Federal de Santa Catarina (UFSC). E-mail: j.fossa@unochapecó.edu.br
} 


\section{Introdução}

A agricultura brasileira se constitui ao longo do processo de desenvolvimento da economia brasileira um setor de destaque. Até o início da efetivação do processo de industrialização (a partir de meados do século XX), a agricultura brasileira por meio do modelo de exportação gerou as divisas e ditou a dinâmica dos processos produtivos do país. A partir de então a agricultura nacional contribuiu para industrialização fornecendo insumos primários, mão de obra e atendendo a crescente demanda urbana por alimentos.

A modernização da agricultura brasileira, conforme Graziano da Silva (1982), foi realizada de forma conservadora, ou seja, não alterou a estrutura agrária, permanecendo a alta concentração da posse da terra. Outro aspecto a destacar é que apesar da mecanização ocorrida, a abundância das terras possibilitou a expansão da produção de forma extensiva por meio da utilização de novas terras. Nesse processo, os pequenos produtores e os trabalhadores rurais permaneceram a margem da modernização e sob os avanços da entrada do capitalismo na agricultura brasileira. Na década de 1980, em consequência da recessão econômica vivenciada no país e o quadro de exclusão dos pequenos produtores rurais das políticas públicas iniciou-se um avanço em termos de reorganização social desse segmento. As lutas e movimentos, especialmente dos sindicatos dos trabalhadores rurais resultaram entre outras conquistas, a criação do Programa Nacional de Fortalecimento da Agricultura Familiar (Pronaf) em 1996.

A partir do Pronaf, o segmento rural familiar passou a contar com uma política pública específica de apoio ao fortalecimento e desenvolvimento das atividades socioprodutivas, por meio da disponibilidade de acesso ao crédito. Desde sua implantação, o programa passou a estar ao alcance de agricultores familiares de todas as regiões do país em termos de contratos assinados e volume de recursos concedidos. Diante disso, adotou-se a seguinte questão problematizadora ao considerar o Pronaf como a principal estratégia de desenvolvimento rural da agricultura familiar: como se deu a distribuição do crédito Pronaf no período 1996-2016 no estado catarinense? E como objetivo este estudo se propôs a analisar o acesso ao crédito Pronaf no estado de Santa Catarina, evidenciando sua evolução em termos de contratos e volume de recursos acessados no período de 1996-2016.

Em termos metodológicos, esse estudo se caracteriza como uma pesquisa bibliográfica, apoiando-se em dados secundários de caráter (quantitativo) e analises a partir desses dados envolvendo aspectos qualitativos. Os dados apresentados foram acessados junto ao Banco Central do Brasil, sendo os dados financeiros do acesso ao crédito rural deflacionados pelo 
INPC para o ano de 2016. A série histórica analisada compreende o período de 1996 a 2016, na qual a apresentamos e discutimos os dados referentes às linhas de crédito de custeio e investimento, valor médio dos contratos, bem como a distribuição por região e municípios do Estado.

Este artigo está estruturado em três seções, além desta introdução. Na segunda seção são apresentados aportes teóricos em relação ao modelo brasileiro de desenvolvimento a partir de uma visão de Celso Furtado (1986), destacando aspectos sobre o processo de desenvolvimento da agricultura brasileira, bem como são tecidos breves considerações referente à conceituação de agricultura familiar e da política pública de crédito rural da agricultura familiar. Na terceira seção são apresentados os dados e análises de distribuição do Pronaf em Santa Catarina. Por fim, são elaboradas algumas considerações finais e proposições de estudos futuros a partir dos resultados aqui encontrados.

\section{Considerações sobre o desenvolvimento rural no Brasil}

O Brasil, país latino-americano, situado ao sul do continente é na visão de Furtado (1986) um típico caso de estudo sobre o subdesenvolvimento. Entretanto, é necessário situar o leitor que Furtado escreve a "Análise do modelo brasileiro" no início dos anos de 1970 e neste período o país - segundo o próprio autor -, era dotado de inúmeras características que legitimavam sua condição de subdesenvolvimento ${ }^{1}$.

Antes de entrarmos nessas características apontadas por Furtado sobre o subdesenvolvimento brasileiro torna-se necessário expressar algumas notas sobre a definição de desenvolvimento. Apesar da complexidade em torno do termo "desenvolvimento", Furtado (2000, p. 150) define que o desenvolvimento consiste em "profundas modificações nas estruturas econômicas e sociais e a elevação do nível de vida como fenômeno persistente".

Em linhas gerais, Favaretto (2006) define o desenvolvimento como um processo evolutivo, de movimento e que busca crescimento e mudanças de longo prazo. Na visão de Beraldo (2016), o desenvolvimento significa a sociedade desejada por meio de um processo histórico de mudança social, que visam à promoção de melhorias a partir de um conjunto de atores e agentes da sociedade. Entretanto, o grupo social dominante que no processo histórico se apropriaram do excedente dando a tônica do processo, da forma em que apenas uma pequena parte da sociedade beneficiou-se desse progresso (FURTADO, 2000).

\footnotetext{
${ }^{1}$ A construção analítica neste item baseia-se na obra "Análise do "modelo" brasileiro" de Celso Furtado. 
As raízes do subdesenvolvimento segundo Furtado (1986) estão diretamente associadas às consequências da revolução industrial, de sobremaneira sob dois aspectos: o primeiro vinculado ao aumento da produtividade pelo progresso técnico que possibilitou ampla expansão de bens e mercadorias em nível mundial; e, o segundo encontra-se relacionado com o padrão de consumo.

O subdesenvolvimento constitui-se fundamentalmente no desdobramento desses aspectos, sendo que esse avanço tecnológico no modelo de econômico em âmbito global serviu mais para modernizar e expandir os hábitos de consumo, do que transformar os processos produtivos em nível mundial. Essa condição, também contribuiu para formação da dependência centro-periferia, especialmente pela imitação dos hábitos de consumo e pela importação de tecnologia (CARDOSO, 1993; FURTADO, 1986).

No caso brasileiro, em meados da segunda metade do século XX o país possuía diversidade em termos industriais (talvez o mais moderno dos países periféricos) e uma agricultura com alta concentração fundiária e de renda, com baixíssimos índices de produtividade (FURTADO, 1986). Além desses dois aspectos, outros dois também são ressaltados por Furtado (1986), o primeiro é que Estado brasileiro se apresentava como principal agente promotor do desenvolvimento; e, o segundo se cristaliza em relação à dependência tecnológica em relação aos países centrais.

A economia capitalista mundial e o ingresso tardio no mercado internacional enquadraram o Brasil, assim como todos os países latinos, como coadjuvante, participando da economia global como exportador de matérias-primas, principalmente alimentos e bens semimanufaturados. Conforme aponta Furtado (1986) a dominação do progresso tecnológico pelos países centrais estabeleceu a dependência econômica também no caso brasileiro.

A partir de meados do século XX o Brasil, mesmo em condição de subdesenvolvimento, acelerou seu processo de industrialização. A industrialização decorreu fundamentalmente a partir dos bens de exportações que possibilitaram o desenvolvimento industrial ligado a esse modelo econômico. Nesse sentido, afirma Furtado, (1986, p. 23), "Seria um equívoco imaginar que esta [industrialização] derivou o seu impulso principal da ação do Estado. O impulso principal originou-se nas próprias forças econômicas [...]”. $\quad$ Nesse período, as ações do Estado eram realizadas no sentido de atenuar as tensões dos setores econômicos em prol do processo de industrialização. Entre essas ações, destaca-se o financiamento do processo de industrialização, especialmente pela captação no mercado internacional.

De acordo com Furtado (1986) os financiamentos eram retirados das indústrias de substituição de importação por meio de taxas e impostos e principalmente por meio de bancos 
estatais (BNDE e Banco do Brasil). Também ocorreram financiamentos por conta da poupança interna, via processo inflacionário, além de sacrifícios em termos de salários em benefício do aumento da produtividade, ou escrito de outra forma, os aumentos de produtividade pela superexploração do trabalho (MARINI, 2011). Para Furtado, a ação do Estado também orientou o desenvolvimento da indústria nacional pelo processo de substituições de importações. Ao referir-se sobre este processo argumenta-se que,

\footnotetext{
Trata-se menos de concorrer com as importações que aumentar uma oferta que sofreu contração. Pelo menos assim ocorreu na primeira fase, quando a capacidade de importar permanecia deprimida. Na fase subsequente a dinâmica da substituição de importação é algo distinta: ela permite que a oferta global de produtos manufaturados cresça mais rapidamente que a importação desses produtos. Furtado (1986, p. 24).
}

A partir de 1964 se estabelece no país novas estratégias para reestabelecer as condições do equilíbrio público, controle da inflação visando eliminar os pontos de estrangulamento. $\mathrm{Na}$ concepção de Furtado (1986) três foram as principais estratégias para retomada da industrialização: i) concentração de riqueza para formação de capital fixo e ampliação do consumo de bens duráveis; ii) redução da taxa do salário real; ii) fomento as exportações por meio de subsídios (aumentar a integração com o mercado mundial). Estas estratégias foram operacionalizadas por meio de instrumentos cambiais, fiscais, creditícios e salariais.

A manutenção da expansão da industrialização passaria pelos seguintes requisitos: i) capacidade de pagamento no exterior; ii) gastos públicos em investimentos estruturais; iii) aumento consideráveis na demanda por bens de consumo. E neste processo o papel do Estado no modelo brasileiro seria assegurar a expansão da demanda por bens duráveis se expanda e promover um novo fluxo de empregos (FURTADO, 1986).

Outro aspecto que se torna válido apresentar é a concepção "Furtadiana" em relação à mentalidade do empresariado brasileiro (a maior parte), que se difere fundamentalmente da burguesia europeia. Essa diferenciação se consolida pelo fato de que esta abriu mão de construir uma sólida base industrial nacional, preferindo contentar-se e beneficiar-se do modelo exportador ${ }^{2}$.

Em síntese, o "modelo" brasileiro de desenvolvimento, conforme a concepção de Furtado (1986) se constituiu em uma tentativa de superação dos limites e entraves estruturais pelo caminho da industrialização. O caminho para superar o subdesenvolvimento por meio da industrialização apresenta-se como um percurso desafiador, pois exige (no caso brasileiro) que

\footnotetext{
${ }^{2}$ Em relação a dependência cultural do empresariado brasileiro consultar: Cardoso e Faletto (1975; 2000) e Furtado (1984).
} 
Revista Catarinense de Economia - RCE

APEC - Associação dos Pesquisadores em Economia Catarinense

1ㅇ Semestre de 2018 - www.apec.pro.br/rce

empresas internacionais progressivamente transfiram o domínio tecnológico e expansão e adequação da demanda interna. Contudo, Furtado (1986) aponta para três problemas fundamentais do modelo brasileiro: i) intensidade e a orientação do processo de concentração de riqueza; ii) criação de empregos no setor moderno, ou seja, funções de tecnologia e inovação; iii) os salários de subsistência. Compreende-se também a partir da contribuição de Furtado (1986) que industrialização brasileira não beneficiou o conjunto da população.

É a partir desta constatação que ingressamos na discussão sobre a estrutura agrária e o papel da agricultura no processo de industrialização. Constata-se que concomitantemente ao processo industrial, ocorreu no Brasil significativas transformações no meio rural que deram condições e também suporte para consolidação da industrialização brasileira. Seguindo na perspectiva "Furtadiana" sobre o modelo brasileiro, surge a necessidade de compreender no contexto histórico, os aspectos que permitiram a alta concentração da terra no Brasil. Nesse sentido, Furtado (1986) aponta que a abundância de terras permitiu a passagem pelo processo de abolição do trabalho servil, sem que as condições de concentração e de domínio da terra fossem alteradas.

O controle e domínio da terra pelas grandes empresas agrícolas foram essencialmente utilizados, para impedir a constituição de outras formas de agricultura no país. Segundo Furtado (1986), os pequenos produtores dificilmente conseguiam a condição da posse da terra e quando na condição de trabalhadores rurais das grandes propriedades enfrentavam péssimas condições de trabalhos e superexploração de sua mão de obra. Assim, constata-se que a posse da terra se constitui como um aspecto determinante da estruturação agrária brasileira. A concentração da posse da terra levou a concentração da renda, e consequentemente deixando a margem uma massa de trabalhadores rurais. O latifúndio brasileiro é um fenômeno político, uma estrutura de poder baseada no apoio do Estado, na exploração da mão-de-obra e o consequente tardio ingresso do progresso técnico na agricultura (FURTADO, 1986).

A alta concentração da terra e a tardia modernização não impediram o progresso agrícola do país, principalmente no que tange a elevação da produção. O processo de industrialização ocorrido no país também acelerou o processo de modernização da agricultura brasileira, tornando-a mais produtiva e com características de uma atividade industrial. A modernização da agricultura causou uma expressiva expulsão de trabalhadores rurais que, em grande parte, migraram ao meio urbano servindo a indústria como mão-de-obra a partir de baixos níveis salariais.

A modernização da agricultura apoiou também a industrialização da agricultura por meio do fornecimento de matérias primas, especialmente em relação à alimentos, visto que, com o 
crescimento dos centros urbanos a demanda por alimentos aumentou significativamente (FURTADO, 1986). Por fim, em uma perspectiva ampla, no Brasil os privilégios levaram a grande concentração da terra, e por seguinte uma forma predatória de atuação que levou a uma condição de extrema concentração de renda nacional (FURTADO, 1986). Neste sentido compreende-se que a agricultura brasileira ocupou (e ocupa) um papel estratégico no desenvolvimento nacional, apesar de ter gerado expressivas externalidades negativas de cunho social em seu processo de modernização.

\subsection{Aportes iniciais sobre o desenvolvimento rural no Brasil}

Para Wanderley (2017, p. 79), o termo desenvolvimento se refere a um "campo de disputas entre concepções de sociedade, que expressam interesses conflitantes de grupos e classes sociais”. Sobre desenvolvimento rural, Kageyama (2008) esclarece que não significa apenas crescimento econômico, mas sim um processo que envolve a melhoria das condições nos aspectos econômicos, sociais, ambientais e políticos. Na visão de Schneider e Tartaruga (2006, p. 17), o desenvolvimento rural pode ser definido como sendo,

\footnotetext{
[...] um processo que resulta de ações articuladas que querem induzir mudanças socioeconômicas e ambientais no ambiente do rural para melhorar a renda, a qualidade de vida e o bem-estar das populações. Dadas as especificidades e particularidades do espaço rural, determinadas pelas condições sociais, econômicas, ambientais e tecnológicas, o desenvolvimento rural se refere a um processo evolutivo, interativo e hierárquico de seus resultados, manifestando-se nos termos dessa complexidade e diversidade no plano territorial.
}

Em continuidade, Favaretto (2006) aponta que a chave do desenvolvimento rural deve estar na melhoria das condições da sociedade em geral e nas novas formas de uso dos recursos naturais, novas formas sociais e novas formas de interação com o sistema econômico. As tendências do desenvolvimento rural preveem maior interação entre o urbano e o rural, preocupações com o ambiental e uma visão holística entre desenvolvimento produtivo e territorial e superação da pobreza no meio rural (FAVARETTO, 2006).

Abordar qualquer análise sobre o desenvolvimento rural no Brasil exige um olhar para estrutura agrária e a concentração da terra nas mãos de poucos, contudo proprietários de grandes latifúndios. Esse processo se deu desde o início da colonização do país, como aponta Graziano da Silva (2001, p. 25) "O início da colonização brasileira se fez com a doação de grandes extensões de terra a particulares, denominadas sesmarias. Daí surgiram os latifúndios escravistas $[\ldots]^{\prime \prime}$. 
Como já mencionamos no item anterior, a grande quantidade de terras disponíveis no país permitiu que a estrutura agrária (concentração da posse) terra permanecesse praticamente inalterada mesmo após o fim do período de escravidão. De um modo geral, é partir deste contexto que se distingue a agricultura brasileira em dois segmentos distintos, o primeiro se constitui pelos grandes latifúndios, enquanto o segundo segmento é formado pelos pequenos produtores, recentemente na literatura nacional chamado de agricultura familiar.

O desenvolvimento teórico a seguir busca apontar alguns subsídios em relação ao desenvolvimento rural, especificamente na interação/relação e disputas entre estes dois segmentos quanto ao processo de modernização da agricultura e integração ao setor industrial nascente ocorrido com maior ênfase a partir da década de 1930. Segundo Sorj (1980) é nesse período se inicia a passagem do eixo da acumulação da agricultura para o setor industrial.

Martine (1991) afirma que a modernização da agricultura brasileira foi conservadora constituindo-se na transformação da agricultura por meio da mecanização tecnológica baseada na agricultura patronal. Na concepção de Graziano da Silva (1981), em sua clássica obra " $A$ modernização dolorosa", a modernização da agricultura brasileira teve um caráter conservador, legitimando a concentração de terra e renda aos grandes produtores capitalistas (empresas rurais).

Para Delgado (2009) o debate e a necessidade da reforma agrária ainda estão colocados diante da sociedade brasileira. Mattei (2016, p. 246) defende que no caso brasileiro a reforma agrária “[...] promova a distribuição das terras e da renda e, ao mesmo tempo, que seja portadora da justiça e da equidade social". Sob a égide da modernização, o capitalismo ingressa plenamente na estrutura rural brasileira potencializando a produção agrícola para o mercado internacional por meio da exportação commodities (GRAZIANO DA SILVA, 1982). Para Martine (1991) a modernização brasileira contou com três fases distintas nos anos 80: i) 19651979 - período onde o crédito rural (principal política agrícola) foi o instrumento utilizado para realização da modernização; ii) 1980-1984 - período de recessão econômica e consequentemente redução dos beneficiados com o crédito rural; iii) 1985-1989 - período marcado pelo significativo incremento da produção agrícola, especialmente direcionadas à exportação.

O período marcado pela modernização da agricultura brasileira proporcionou certa transformação dos pequenos produtores, contexto este denominado por Graziano da Silva (1981) de "novo camponês". Esse "novo camponês" se caracteriza pelo intenso trabalho familiar (assim como o "velho camponês"), só que em uma nova condição de total submissão ao capital, submissão às agroindústrias e as cooperativas de produção. É o capital que dita às 
Revista Catarinense de Economia - RCE

APEC - Associação dos Pesquisadores em Economia Catarinense

1ㅇ Semestre de 2018 - www.apec.pro.br/rce

regras na propriedade, dessa forma retirando a autonomia desse pequeno produtor rural (GRAZIANO DA SILVA, 1981).

Para Sorj (1980) a integração ao capital não significa melhores condições para o pequeno produtor, antes pelo contrário, o pequeno produtor rural este se vê explorado de todas as formas. Uma das formas de exploração diz respeito às técnicas e modos de produção (GRAZIANO DA SILVA, 1981). Outra forma ocorre no caso da integração com a agroindústria, Renk e Winckler (2013) apontam que os agricultores se tornam reféns das mesmas no que diz respeito à aquisição de insumos. As imposições das agroindústrias restringem até a produção para o autoconsumo familiar na propriedade, restringindo assim uma das principais características desse segmento social (GAZOLLA, 2004). O "novo camponês", como apontou Graziano da Silva (1981), se torna (por uma questão de sobrevivência) um ator político, que a partir da modernização da agricultura além de lutar pelo acesso à terra também deve colocar contra a superexploração do capital.

O processo de modernização da agricultura brasileira foi marcado pelas ações do Estado através de políticas públicas. Sobre essa intervenção do governamental, Leite (2001) afirma que o Estado agiu de forma a privilegiar os interesses dos grandes produtores rurais empresariais. Para Delgado (2001) essas políticas foram desenvolvidas tanto no âmbito macroeconômico como em políticas setoriais. As políticas macroeconômicas afetam os grandes agregados da economia como salários, taxas de juros, taxa de câmbios e nível geral de preços. As políticas setoriais dividem-se em políticas agrícolas e políticas agrárias. As primeiras englobam políticas de mercado, pesquisa e desenvolvimento bem como aspectos estruturais; enquanto a segunda, trata-se da questão da posse da terra, redistribuição e regularização, ou seja, uma política eminentemente estrutural (DELGADO, 2001) ${ }^{3}$.

Ainda em relação à participação do Estado no meio rural brasileiro outro instrumento utilizado são as políticas ou programas com determinados objetivo específico. Na concepção de Delgado (2001, p. 26) "Essas políticas são usualmente dirigidas a segmentos empobrecidos do campesinato, não integrados à modernização produtiva [...]”. Para Grisa e Schneider (2015) a Constituição de 1988 pode ser considerada o marco inicial das transformações no que se refere às relações entre o Estado e a sociedade civil. Nesse sentido, a agricultura familiar a partir da década de 1990 passa a ser reconhecida e contemplada com políticas específicas.

\footnotetext{
${ }^{3}$ Delgado (2001, p. 24) “[...] A política agrária está assentada na concepção de que a propriedade e a posse da terra são fatores especiais que condicionam a estrutura da produção agrícola [...]". 
O Pronaf surge neste cenário, e é implantado em 1996 em resposta às reivindicações dos pequenos produtores. Segundo Mattei (2006) o Pronaf é criado fundamentalmente pela ação e lutas dos sindicatos dos trabalhadores rurais e por um estudo em parceria entre FAO/INCRA.

\subsection{Agricultura familiar e o Programa Nacional de Fortalecimento da Agricultura Familiar}

Os referenciais teóricos, há muitos anos, classificam e distinguem a agricultura brasileira em certa dualidade entre agricultura patronal/empresarial e agricultura familiar. Neste item, centralizaremos a análise e a caracterização na agricultura familiar. Para Graziano da Silva (1981), os pequenos produtores rurais assumem diversas definições no que se refere à sua nomenclatura como, por exemplo, minifundistas, pequenos posseiros, pequenos. Grisa e Schneider (2015) apontam que nas últimas três décadas a literatura usualmente vem nominando os pequenos produtores rurais de agricultores familiares.

Entretanto parte-se do entendimento que os conceitos se alteram com o passar dos anos, conforme ressaltado por Seyferth (2011, p. 397), ao referir que "as definições são ferramentas do pensamento e não verdades que duram para sempre”. Na expressiva contribuição de Mattei (2006), esse grupo de agricultores familiares também são designados como pequenos produtores, produtores familiares, produtores de baixa renda ou agricultores de subsistência.

Para Guanziroli (2007), uma das possibilidades para classificar a agricultura familiar é a partir das formas e organização social do seu processo produtivo que essencialmente se caracterizam pelas seguintes características: mão de obra familiar; maior parte da renda advinda do trabalho familiar na propriedade; produção diversificada; e, estabelecimentos rurais familiares. Por isso, em muitas situações, a delimitação de tipos de agricultura serve ao propósito de oferecer programas e políticas específicas a determinada categoria.

Para Wanderley (2001), a agricultura familiar pode ser compreendida como aquela em que a família é a proprietária dos meios de produção e ao mesmo tempo assume o trabalho na propriedade rural, apresentando, assim, uma significativa diversidade nas formas sociais de organização. Na visão de Abramovay (2003) a agricultura familiar apresenta multiplicidade de atores sociais (que vão muito além da produção agropecuária), os quais são sustentados pelos laços sociais individuais e de suas organizações.

Para Moreira (2013), as definições das expressões da agricultura familiar se constituem em elementos criteriosos de identificação dos sujeitos analisados e de seus territórios, seu 
Revista Catarinense de Economia - RCE

APEC - Associação dos Pesquisadores em Economia Catarinense

1ㅇ Semestre de 2018 - www.apec.pro.br/rce

contexto social, econômico e cultural. No entendimento de Schneider (2009), os estudos da agricultura familiar exigem análises sociológicas de múltiplas dimensões sobre a ampla diversidade de suas formais sociais.

Os estudos sobre a agricultura familiar se justificam e assumem expressivos significados, pois a análise dessa categoria, sua dicotomia com a grande propriedade e as relações com a sociedade vão muito além da questão produtiva (MATTEI, 2015). A esse respeito, Costa (2013) ratifica essa condição social afirmando que o modo de vida e as relações sociais da agricultura familiar não podem ser explicados meramente por estatísticas.

O debate sobre desenvolvimento rural familiar no Brasil tem sido configurado de diversas formas e perante distintos focos. Embora as diversas abordagens mobilizadas para se explicar e orientar os cursos desse debate, a redução das desigualdades sociais e a promoção de vida mais digna no campo são metas e indicadores recorrentemente mobilizados no meio acadêmico e político para se discutir resultados de processos de desenvolvimento (SILVA, 2015, p. 22).

Em uma perspectiva de conceituação institucional, a Lei n. 11.326/2006 classifica a categoria da agricultura familiar como sendo aquela que: i) não detenha, a qualquer título, área maior do que 04 módulos fiscais; ii) utilize predominantemente mão de obra da própria família nas atividades econômicas do seu estabelecimento ou empreendimento; iii) tenha renda familiar predominantemente originada de atividades econômicas vinculadas ao próprio estabelecimento ou empreendimento; e, iv) dirija seu estabelecimento ou empreendimento com sua família (BRASIL, 2006).

Neste sentido, as análises teóricas explicativas em relação à agricultura familiar devem ser desenvolvidas a partir de um olhar de várias faces e perspectivas. Entre estas perspectivas estão o modo de vida, reprodução social, sucessão familiar, papel do Estado, produção, relações com o mercado capitalista entre outros inúmeros temas são fundamentais para o entendimento desse importante segmento social. É neste contexto que se legitima e se justifica a importância de pesquisas nesta temática.

Em relação ao processo histórico de constituição da agricultura familiar no estado de Santa Catarina, realiza-se breves considerações em âmbito geral. As terras do Sul do país estiveram ao longo de sua formação entre diversas disputas territoriais. Em Santa Catarina ocorreram lutas entre Portugal e Espanha, Brasil e Argentina, Santa Catarina e Paraná e em meados da segunda década do século XX a guerra do Contestado. Essas disputas influenciaram a "ocupação" territorial especialmente na região Oeste do Estado. As ações estatais impulsionaram a viabilização das empresas colonizadoras, que por sua vez atraíram 
Revista Catarinense de Economia - RCE

APEC - Associação dos Pesquisadores em Economia Catarinense

1ㅇ Semestre de 2018 - www.apec.pro.br/rce

principalmente imigrantes (colonos) e descendentes de europeus, em boa medida do Rio Grande do Sul (WERLANG, 2006).

Na visão de Mattei (2016) essa trajetória histórica da agricultura familiar na região Sul do país ocasionou uma diversificação produtiva, e consequentemente uma diferenciação social entre os agricultores familiares. O estado de Santa Catarina se coloca como um dos principais produtores agrícolas do país, sendo expressiva presença da agricultura familiar. De acordo com o Censo Agropecuário de 2006, 87\% dos estabelecimentos rurais do Estado pertencem à agricultura familiar. Esse desempenho, por sua vez é fundamentalmente determinado pela presença da agricultura familiar e sua força produtiva no Estado. Este cenário posiciona Santa Catarina entre os estados brasileiros que mais acessam o programa de crédito Pronaf desde sua implantação em 1996.

Por sua vez, o Pronaf, constituído em 1996, se apresesenta com a finalidade de atender especificamente a categoria de agricultores familiares. Grisa, Wesz Junior e Buchweitz (2014) afirmam que a criação do Pronaf significou aos agricultores familiares à passagem de uma condição de produtores de subsistência e/ou pequenos agricultores, para uma condição de reconhecimento devido ao estabelecimento de uma a política pública exclusivamente destinada à agricultura familiar.

Estabelecido a partir do Decreto Presidencial no.. 1.946/1996, o programa oferece crédito rural com formas de pagamento de longo prazo e com baixa percentagem de juros (MATTEI, 2014). A estrutura do programa, bem como seus objetivos e finalidades foram desenhados a partir de estudos da FAO/INCRA e do Programa de Valorização da Pequena Produção Rural (PROVAPE), tendo como principal finalidade do programa a concessão de uma linha de crédito específica para agricultura familiar (BIANCHINI, 2015).

Nesse sentido Grisa e Schneider (2015, p. 29) reafirmam que "O Pronaf se constitui na principal política agrícola para agricultura familiar (tanto em número de beneficiários, capilaridade nacional e recursos aplicados) [...]”. Essa condição se evidenciou a partir do ano de 2003, onde o governo federal elegeu a agricultura familiar como prioridade na estratégia de desenvolvimento. Esta priorização resultou em expressivo aumento no volume de recursos disponibilizados.

No período entre 1996 a 2002, o valor financiado passou de $\mathrm{R} \$ 1,9$ bilhões para $\mathrm{R} \$ 6,5$ bilhões. Já no período de 2003 a 2010 os valores passaram de R \$ 6,7 bilhões para R \$ 17,9 bilhões e no ano de 2014 foi registrado o maior volume de crédito disponibilizado desde a implantação do Pronaf, R \$ 29,2 bilhões. O número de contratos também se expandiu de forma mais intensa a partir de 2003, passando de pouco mais de 800 mil em 2002 para 1,5 milhões de 
Revista Catarinense de Economia - RCE

APEC - Associação dos Pesquisadores em Economia Catarinense

1ㅇ Semestre de 2018 - www.apec.pro.br/rce

contratos em 2010. O maior número de contratos foi registrado em 2006 com 2.5 milhões de operações.

Para Mattei (2015, p. 13) esses avanços ocorreram porque “[...] houve um processo de inclusão de novos agricultores como beneficiários dessa política pública", isto porque para o autor houve o "[...] cumprimento das promessas do Governo Lula (2002), que a partir de 2003 elegeu o apoio à agricultura familiar como uma das prioridades de sua política de desenvolvimento rural do país”. Em complemento, Aquino e Schneider (2015) apontaram que o Pronaf, com o passar dos anos, foi entendido especialmente pelos seus gestores públicos, como política pública capaz de estabelecer uma estratégia em âmbito nacional de ampliação da diversidade social da agricultura familiar no meio rural.

Os recursos acessados pelos agricultores familiares e o número de contratos efetivados desde o início das operações do Pronaf tiveram incremento significativo, e consequentemente possibilitaram a expansão do programa em todas as regiões do país. Nesse sentido, Wanderley (2017, p. 69) afirma que "Não resta dúvida que o PRONAF representou um salto significativo em relação às políticas anteriormente praticadas”. Entretanto, o Pronaf, na condição de política pública, ainda possui diversos desafios a serem superados, com destaque para ainda maior ampliação do programa especialmente aos menos capitalizados e fortalecimento de suas linhas específicas de atuação, como o Pronaf Jovem e Mulher.

\section{A distribuição do crédito Pronaf em Santa Catarina}

Inicialmente destaca-se que no período de 1996 a 2016 o estado de Santa Catarina efetivou o significativo número de 2.341 .832 contratos de crédito rural por meio do Pronaf, em que maior parte dos contratos foram destinados à finalidade de custeio, no qual totalizando 1.886.833 contratos representando $80,6 \%$ em relação ao total. Os contratos de investimentos somaram no período 454.969 , representando $19,4 \%$ do total de contratos. Os contratos de industrialização foram registrados apenas no ano de 2016 (ano de início dessa modalidade de crédito) e totalizaram apenas 30 casos.

$\mathrm{O}$ alto percentual destinado para a finalidade de custeio significa a dependência por parte dos agricultores no que tange a viabilização de suas atividades produtivas, o que Toledo (2009) classificou como "círculo vicioso" em torno do Pronaf. Além da dependência, outro aspecto restritivo do programa é o fato de concentrar a maior parte dos recursos em apenas algumas culturas, em detrimento do apoio a diversificação da produção. 
Em consequência o incremento dos contratos para investimento no Estado foram restritos no período entre 1996 e 2016, entretanto houve evolução desta finalidade a partir do ano de 2006. Neste ano de 2006, os contratos de investimento representaram $18,8 \%$ em relação ao total, tiveram crescimento de sua participação total sendo que em 2016 registrou-se 27,5\% do total dos contratos somente para a linha de investimento. Essa evolução, de certa forma, impulsionou a ampliação da produção, estrutura e modernização das propriedades de agricultura familiar.

Gráfico 1 - Número de contratos totais e de custeio efetivados via Pronaf por agricultores familiares em Santa Catarina, no período de 1996 a 2016.

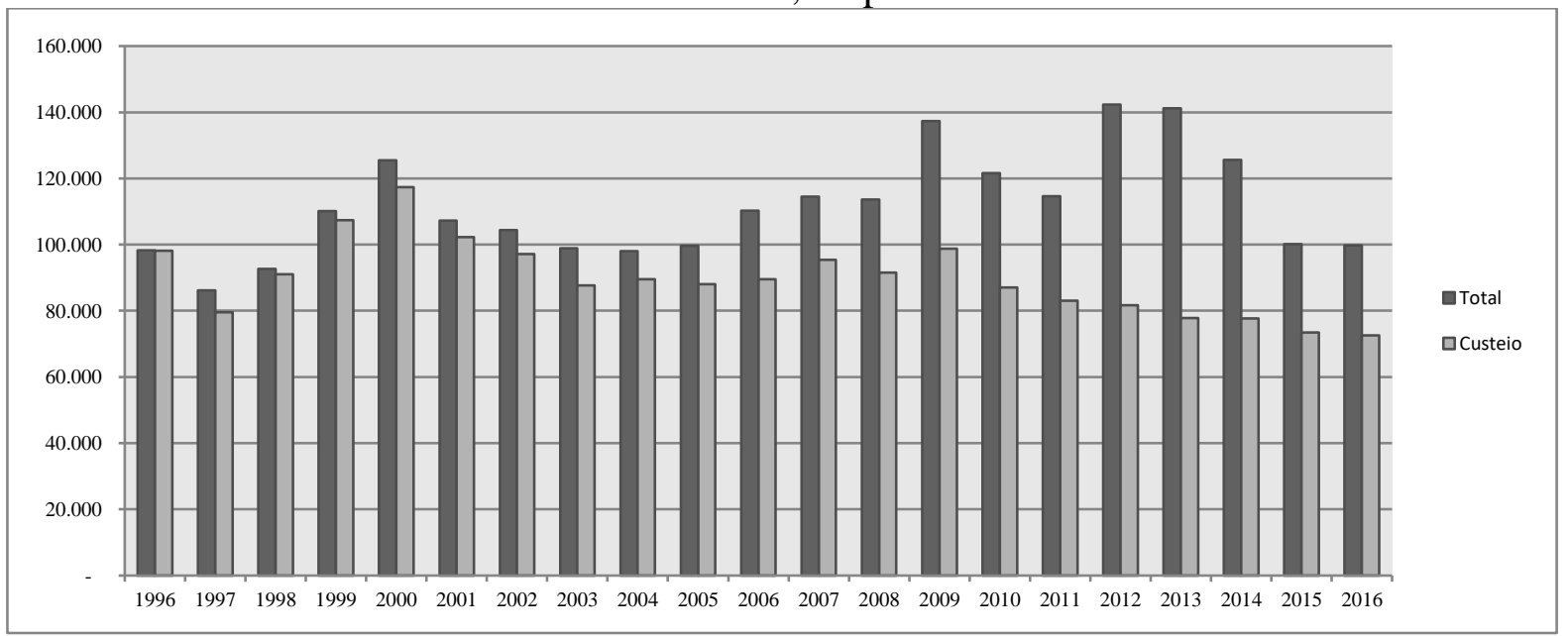

Fonte: Elaboração do autor com base em dados do Banco Central do Brasil (2016).

No que tange a distribuição entre as regiões do Estado catarinense, os contratos totais (custeio, investimento e industrialização) a região Oeste é a que concentra o maior número de contratos, com percentual de 58\% dos contratos do estado no período de 1996 a 2016. Essa concentração evidencia a predominância de um modo de agricultura, que demonstra depender do crédito rural para o desenvolvimento das atividades produtivas, em que é necessário realizar investigações, que apontem em que medida o crédito se tornou um recurso indispensável à atividade.

O Vale do Itajaí encontra-se como a segunda região com maior número de contratos efetivados representado por $12 \%$ (279.953), na sequência as regiões Sul, Norte, Serrana e Litoral com 9,2\% (213.952), 8,8\% (206.359), 8\% (189.950) e 4\% (93.675) contratos por região respectivamente. Esta condição, assim como citado anteriormente, também pode estar associada às condições e estruturas da agricultura familiar em cada uma das regiões.

No entanto, ao se realizar a comparação do número de contratos 2016 com o número de contratos 1996, é possível verificar a expansão de cada região em relação a si mesma, 
efetivando outro cenário. Dessa forma, a região Serrana foi a que mais expandiu em relação ao número de contratos com índice ${ }^{4}$ de 4,92 , seguida da Região Litorânea que registrou um índice de 2,95. As regiões do Vale do Itajaí e Norte ficaram com índices de 1,67 e 1,61 respectivamente. E por fim a região Oeste com 0,79 e Sul com índice de 0,65.

Esses índices regionais demonstram a expansão do Pronaf no Estado no período em análise, e, como reflexo, atualmente está presente nos 295 municípios catarinenses. Os dados revelam a redução em termos relativos da concentração dos contratos realizados na região Oeste, que passou de 70,6\% em 1996 para 55,2\% em 2016. No caso dessa região, essa diminuição do índice de participação nos contratos ocorreu em detrimento ao aumento no número de contratos para as demais regiões no primeiro ano do Pronaf. Tal ocorrência pode ser explicada pelo acesso à informação aos agricultores familiares, que passam a conhecer a política e utilizarem para o desenvolvimento das atividades produtivas. Os números de contratos por região e ano estão dispostos na Tabela 1.

Tabela 1 - Número de contratos totais realizados nas regiões de Santa Catarina via Pronaf no período de 1996 a 2016.

\begin{tabular}{crrrrrrr}
\hline Ano/Região & Litoral & \multicolumn{1}{c}{ Oeste } & \multicolumn{1}{c}{ Norte } & Serrana & \multicolumn{1}{c}{ Sul } & Vale do Itajaí & \multicolumn{1}{c}{ Total } \\
\hline 1996 & 1.554 & 69.337 & 5.404 & 1.958 & 11.357 & 8.615 & 98.225 \\
1997 & 2.936 & 39.329 & 9.730 & 3.936 & 14.126 & 16.097 & 86.154 \\
1998 & 2.498 & 45.122 & 10.846 & 5.475 & 13.973 & 14.810 & 92.724 \\
1999 & 2.679 & 60.350 & 12.346 & 7.632 & 13.332 & 13.792 & 110.131 \\
2000 & 3.339 & 67.027 & 14.803 & 6.940 & 16.023 & 17.341 & 125.473 \\
2001 & 3.288 & 59.504 & 12.169 & 6.281 & 12.433 & 13.548 & 107.223 \\
2002 & 2.658 & 67.142 & 9.902 & 6.539 & 8.308 & 9.884 & 104.433 \\
2003 & 2.894 & 64.205 & 8.506 & 7.513 & 6.352 & 9.405 & 98.875 \\
2004 & 4.129 & 59.303 & 9.306 & 8.749 & 6.838 & 9.698 & 98.023 \\
2005 & 4.615 & 59.181 & 8.242 & 9.123 & 8.371 & 10.101 & 99.633 \\
2006 & 5.499 & 63.171 & 8.952 & 10.805 & 10.225 & 11.650 & 110.302 \\
2007 & 5.718 & 63.473 & 9.932 & 11.691 & 10.335 & 13.287 & 114.436 \\
2008 & 6.085 & 61.191 & 10.227 & 11.723 & 10.525 & 13.826 & 113.577 \\
2009 & 5.073 & 83.142 & 10.122 & 14.762 & 10.204 & 14.054 & 137.357 \\
2010 & 7.212 & 67.582 & 10.241 & 10.544 & 10.710 & 15.333 & 121.622 \\
2011 & 6.671 & 67.394 & 8.708 & 10.002 & 8.222 & 13.595 & 114.592 \\
2012 & 5.325 & 92.028 & 9.542 & 12.552 & 8.397 & 14.457 & 142.301 \\
2013 & 6.133 & 86.181 & 10.365 & 12.363 & 9.333 & 16.876 & 141.251 \\
2014 & 6.169 & 71.423 & 10.318 & 11.899 & 10.036 & 15.767 & 125.612 \\
2015 & 4.616 & 56.769 & 7.982 & 9.834 & 7.452 & 13.464 & 100.117 \\
2016 & 4.584 & 55.059 & 8.716 & 9.629 & 7.430 & 14.353 & 99.771 \\
\hline Total & 93.675 & 1.357 .913 & 206.359 & 189.950 & 213.982 & 279.953 & 2.341 .832 \\
\hline
\end{tabular}

Fonte: Elaboração dos autores com base em dados do Banco Central do Brasil (2016).

Assim como ocorre a prevalência do número de contratos de crédito de custeio no estado de Santa Catarina, em nenhuma região de forma isolada rompe de forma acentuada essa

\footnotetext{
4 Índice diz respeito a seguinte divisão: Número de contratos 2016/1996.
} 
Revista Catarinense de Economia - RCE

APEC - Associação dos Pesquisadores em Economia Catarinense

1ㅇ Semestre de 2018 - www.apec.pro.br/rce

condição (média do estado no período 81,9\%), as quais permanecem entre 80,6\% e 86,9\%. Em termos absolutos destaca-se a região Oeste que já no ano de 2015 ultrapassou a marca de um milhão de contratos de custeio, finalizando o ano de 2016 com 1.074.987 contratos efetivados.

Em contrapartida, o acesso ao crédito de investimento ainda se apresenta de forma modesta (comparativamente ao crédito de custeio) em todas as regiões, quando se observa o conjunto da série histórica. Entretanto, a partir de 2006 a linha de crédito apresenta crescimento em relação ao número de contratos totais do Estado, chegando a seu ápice em 2014 quando atingiu 44,9\% do total de contratos. Tal evolução foi impulsionada a partir do Programa Mais Alimentos $^{5}$, que foi, majoritariamente, utilizado para a aquisição de maquinário agrícola, com destaque para a compra de tratores de pequeno porte.

$\mathrm{O}$ acesso ao crédito de investimento para o agricultor familiar significa o fortalecimento de suas ações enquanto produtor, pois oportuniza condições para início e ampliação da produção, e consequentemente fortalece suas relações com os atores e o mercado, os quais poderão interferir na gestão e nos modos de produção da propriedade.

Em relação ao montante de recursos financeiros contratados pelo estado de Santa Catarina, os mesmos tiveram expressivo crescimento desde 1996 (ano de implantação do Pronaf). No primeiro ano de implantação o Estado contratou $\mathrm{R} \$ 495$ milhões de reais, enquanto em 2016 o valor foi de $\mathrm{R} \$ 2,7$ bilhões de reais, este valor representa mais de cinco vezes ao de 1996. O maior volume de recursos contratados foi no ano de 2014, quando o valor ultrapassou os $\$ 3,4$ bilhões de reais. Os resultados de 2015 e 2016 foram abaixo do nível de 2014, principalmente pelos cenários econômico e político instáveis vivenciado no país.

A taxa média anual de crescimento dos recursos no Estado foi de $10,4 \%$, sendo que a partir do ano de 2003 ocorreu significativa expansão dos recursos contratados até o ano de 2015, onde a queda em relação a 2014 foi de 26,5\%. Uma investigação junto a agricultores rurais e demais atores relacionados na atividade, seria demasiadamente cara e dispensaria elevado tempo para procurar entender, de que maneira os cenários econômico e político brasileiro podem ter interferido nessa significativa redução.

A expansão do programa, em termos de volume de recursos na comparação com a evolução percebida em termos país, aponta que os recursos do Pronaf cresceram de forma mais acentuada e/ou significativa no território nacional. Tal ocorrência deve-se ao fato que, em termos relativos, os financiamentos no Estado cresceram no período aproximadamente $550 \%$, sendo que no país este percentual superou os $41.000 \%$.

\footnotetext{
${ }^{5}$ Mais Alimentos: consiste de é uma linha de crédito do Pronaf que financia investimentos em infraestrutura produtiva da propriedade familiar.
} 
Gráfico 2 - Evolução do montante de recursos financeiros acessados via Pronaf por agricultores familiares em Santa Catarina, no período de 1996 a 2016.

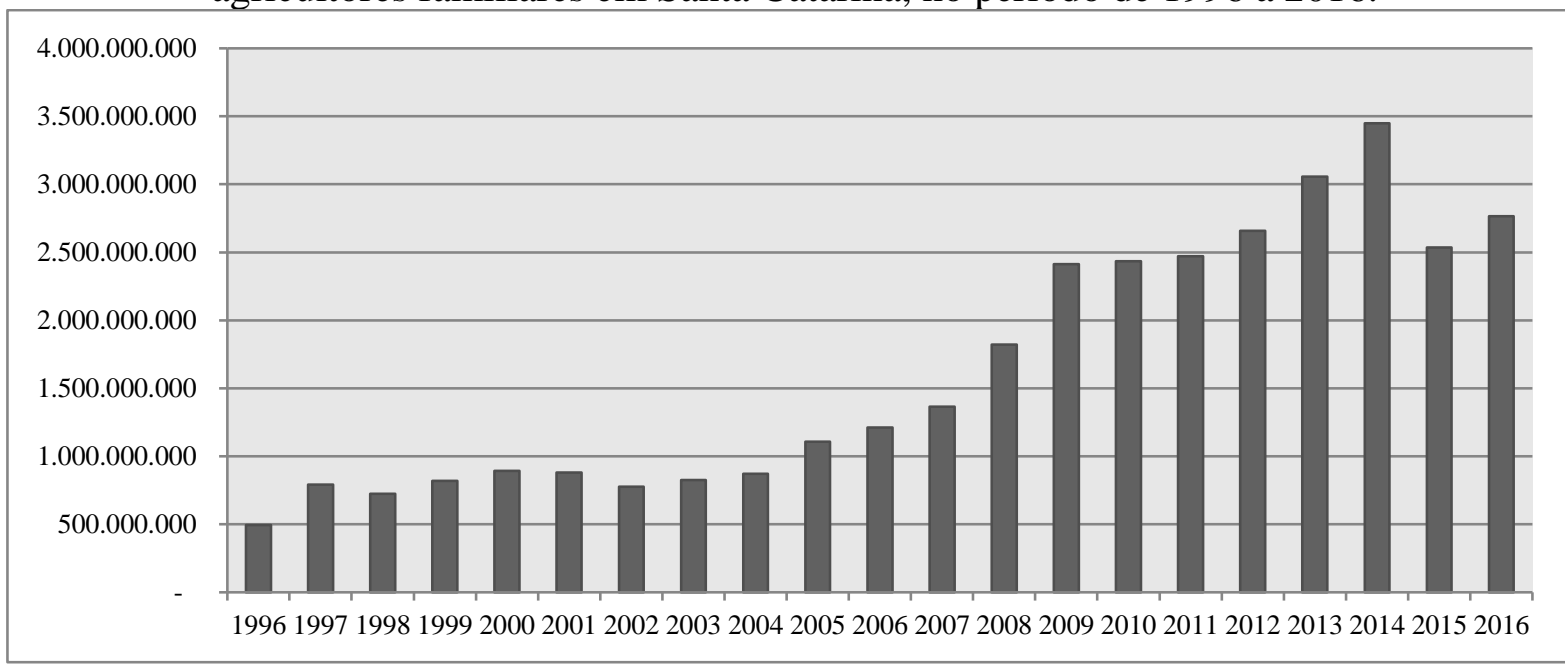

Fonte: Elaboração do autor com base em dados do Banco Central do Brasil (2016).

- Valores deflacionados para o ano de 2016 pelo INPC.

Este aspecto ocorreu desde o primeiro ano de implementação do Pronaf. Neste contexto, Santa Catarina se colocou entre as maiores unidades federativas contratantes, contudo, com o crescimento e expansão do programa em todas regiões federativas, o crescimento da participação relativa do Estado apresentou-se em menor proporção.

Gráfico 3 - Evolução percentual do montante de recursos financeiros acessados no Brasil e em Santa Catarina via Pronaf no período de 1996 a 2016.

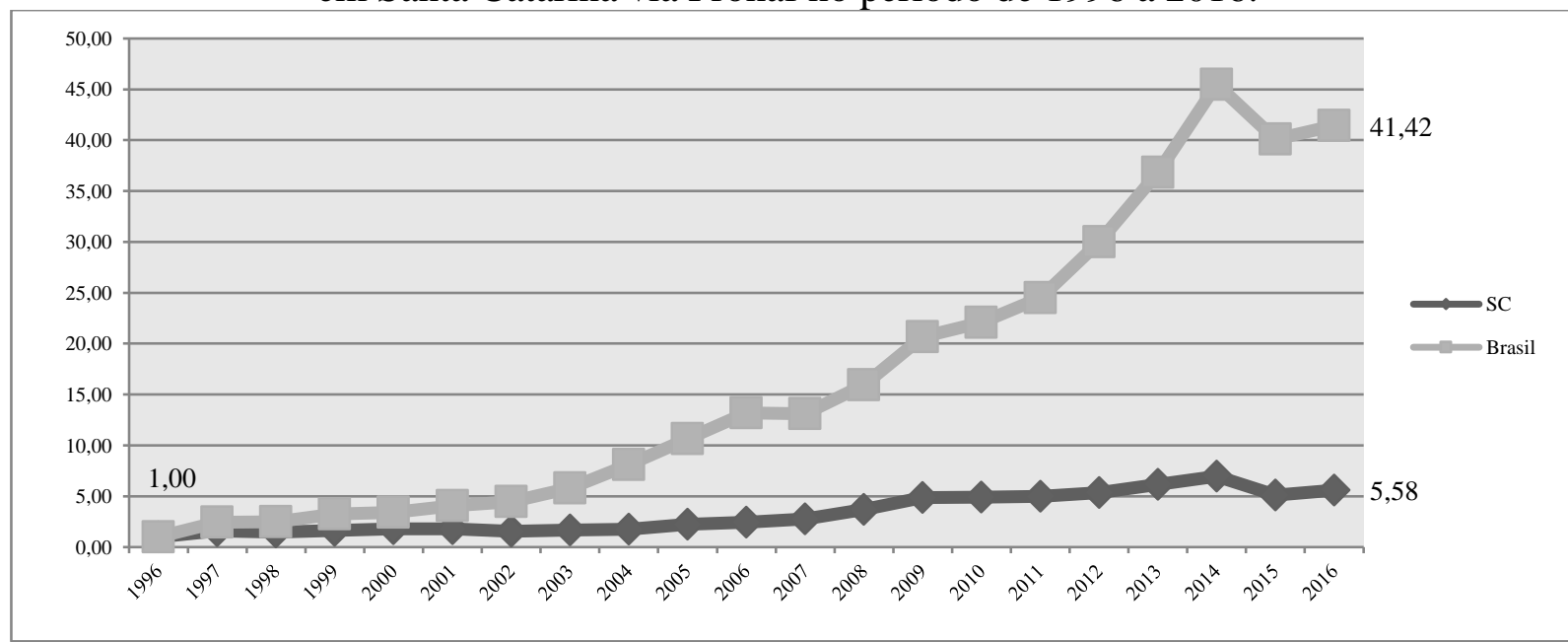

Fonte: Elaboração do autor com base em dados do Banco Central do Brasil (2016).

- Índices de evolução obtidos a partir de 1996, sendo este ano Base $=1$.

Em relação ao volume de recursos por finalidade no Estado, informa-se que o crédito de custeio concentrou a maior parcela dos recursos, sendo que no período essa linha de crédito representou em média 70,5\% do total dos financiamentos contratados no território catarinense. Entretanto, o crédito de investimento no decorrer dos anos foi ganhando "espaço", e nos últimos 
10 anos (2007-2016) representou 42,9\% do total. O crédito Pronaf para industrialização foi registrado apenas em 2016, e representou 4,3\% em relação ao total do Estado.

Este incremento ocorrido na linha de crédito de investimento assume papel importante para estrutura produtiva do segmento rural familiar, pois além de possibilitar a melhoria das condições de trabalho por meio da modernização dos equipamentos e dos métodos de trabalho, também tende a proporcionar condições para o aumento da produção e da produtividade.

Tabela 2 - Montante de recursos financeiros acessados via Pronaf por finalidade contratados em Santa Catarina, no período de 1996 a 2016.

\begin{tabular}{|c|c|c|c|c|c|c|c|c|}
\hline Ano & Valor Custeio & $\%$ & $\begin{array}{c}\text { Valor } \\
\text { Investimento }\end{array}$ & $\%$ & $\begin{array}{c}\text { Valor } \\
\text { Industrialização }\end{array}$ & $\%$ & Valor Total & $\%$ \\
\hline 1996 & 495.112 .883 & 99,9 & 468.338 & 0,1 & -- & -- & 495.581 .221 & 100,0 \\
\hline 1997 & 597.686 .378 & 75,4 & 195.046 .782 & 24,6 & -- & -- & 792.733 .161 & 100,0 \\
\hline 1998 & 681.780 .137 & 94,1 & 42.868 .954 & 5,9 & -- & -- & 724.649 .091 & 100,0 \\
\hline 1999 & 767.841 .504 & 93,5 & 53.028 .964 & 6,5 & -- & -- & 820.870 .468 & 100,0 \\
\hline 2000 & 818.655 .783 & 91,8 & 73.374 .337 & 8,2 & -- & -- & 892.030 .120 & 100,0 \\
\hline 2001 & 753.304 .243 & 85,5 & 127.974 .611 & 14,5 & -- & -- & 881.278 .853 & 100,0 \\
\hline 2002 & 612.103 .756 & 78,8 & 164.317 .198 & 21,2 & -- & -- & 776.420 .954 & 100,0 \\
\hline 2003 & 591.633 .296 & 71,7 & 233.658 .759 & 28,3 & -- & -- & 825.292 .055 & 100,0 \\
\hline 2004 & 682.713 .645 & 78,4 & 188.492 .636 & 21,6 & -- & -- & 871.206 .280 & 100,0 \\
\hline 2005 & 814.943 .543 & 73,6 & 291.828 .554 & 26,4 & -- & -- & 1.106 .772 .097 & 100,0 \\
\hline 2006 & 866.738.131 & 71,5 & 345.694 .359 & 28,5 & -- & -- & 1.212 .432 .490 & 100,0 \\
\hline 2007 & 1.015 .308 .529 & 74,3 & 350.756 .956 & 25,7 & -- & -- & 1.366 .065 .485 & 100,0 \\
\hline 2008 & 1.193 .835 .915 & 65,5 & 629.083 .749 & 34,5 & -- & -- & 1.822 .919 .664 & 100,0 \\
\hline 2009 & 1.266 .579 .981 & 52,5 & 1.147 .302 .875 & 47,5 & -- & -- & 2.413 .882 .856 & 100,0 \\
\hline 2010 & 1.286 .404 .830 & 52,8 & 1.147 .809 .261 & 47,2 & -- & -- & 2.434.214.091 & 100,0 \\
\hline 2011 & 1.309 .376 .258 & 53,0 & 1.161.304.939 & 47,0 & -- & -- & 2.470 .681 .197 & 100,0 \\
\hline 2012 & 1.423 .493 .841 & 53,6 & 1.234 .064 .399 & 46,4 & -- & -- & 2.657 .558 .241 & 100,0 \\
\hline 2013 & 1.505 .115 .390 & 49,3 & 1.550 .925 .777 & 50,7 & -- & -- & 3.056 .041 .168 & 100,0 \\
\hline 2014 & 1.569 .396 .841 & 45,5 & 1.879 .021 .458 & 54,5 & -- & -- & 3.448 .418 .299 & 100,0 \\
\hline 2015 & 1.578 .774 .329 & 62,3 & 955.477 .087 & 37,7 & -- & -- & 2.534 .251 .416 & 100,0 \\
\hline 2016 & 1.605 .805 .102 & 58,1 & 1.041 .324 .835 & 37,7 & 117.808 .971 & 4,3 & 2.764 .938 .908 & 100,0 \\
\hline
\end{tabular}

Fonte: Elaboração do autor com base em dados do Banco Central do Brasil (2016).

- Valores deflacionados para o ano de 2016 pelo INPC.

Esta linha caracteriza-se por não limitar seus efeitos apenas no ano de contratação, mas também gerar efeitos ao longo dos anos posteriores a sua contratação, ou seja, o investimento se dilui em longo prazo. Contudo, ressalta-se, novamente, que a evolução na linha de investimento em comparação com o restante do país, teve crescimento acentuado em menor grau. Santa Catarina registrou crescimento de $27,2 \%$, enquanto o Brasil obteve crescimento de $67,8 \%$. Esse fato também se justifica pela expansão do programa nos demais Estados da federação. O Gráfico 4 demostra tal evolução em relação a linha de investimento no comparativo de Santa Catarina com o Brasil.

O valor médio dos contratos teve um aumento significativo no período, pois como já destacado, a quantidade de contratos na comparação 1996/2016 manteve-se constante, enquanto o volume de recursos na mesma comparação teve um incremente superior a 5,5 vezes. O valor médio do crédito custeio apresentou no período um crescimento linear, evidenciando de algum modo a necessidade cada vez maior de investimento para financiamento da produção 
por parte do agricultor. O valor médio passou de R \$ 5 mil em 1996 para mais de R \$ 22 mil em 2016.

Gráfico 4 - Comparativo da evolução do montante de recursos da linha Pronaf de investimento acessados no Brasil e em Santa Catarina via Pronaf no período de 1996 a 2016.

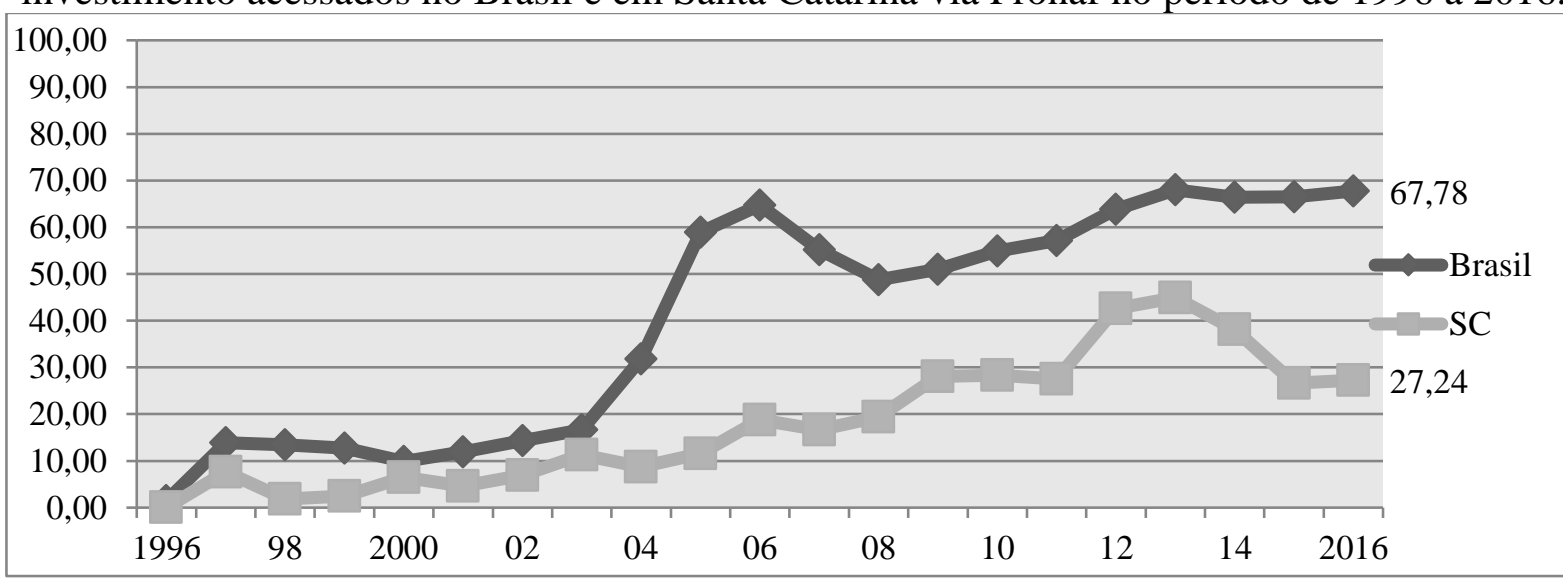

Fonte: Elaboração do autor com base em dados do Banco Central do Brasil (2016).

- Índices de evolução obtidos a partir de 1996, sendo este ano Base = 1 .

Gráfico 5 - Valor médio dos contratos de custeio e investimento acessados no em Santa Catarina via Pronaf no período de 1996 a 2016.

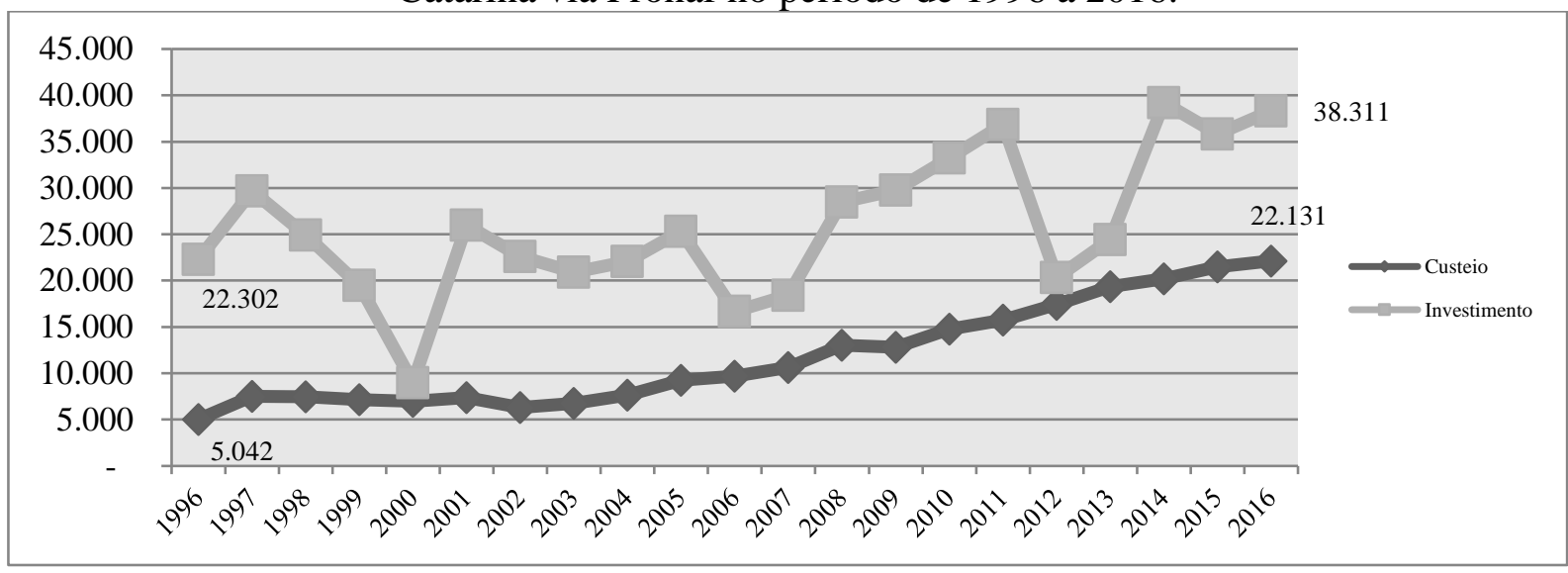

Fonte: Elaboração do autor com base em dados do Banco Central do Brasil (2016).

- Valores deflacionados para o ano de 2016 pelo INPC.

O valor médio dos contratos de investimentos também teve incremento, passando de $\mathrm{R} \$$ 22 mil em 1996 para R\$ 38 mil em 2016, apesar de que em alguns anos registraram-se quedas no valor médio; mas no período a tendência foi de crescimento. Cabe ressaltar que no período 1996-2016 a variação do valor médio da linha de investimento foi pouco mais de 70\%, enquanto a variação do valor médio na linha de custeio variou $439,0 \%$.

No que se refere à distribuição entre as regiões do Estado, quanto ao volume de recursos financeiros contratados, a região Oeste foi responsável pela contratação do maior volume, que ao longo da série histórica representou 55,8\% do total. Em 2016, por exemplo, dos R\$2,7 
bilhões contratados pelo Estado, R \$ 1,5 bilhões foram pelos agricultores familiares da região Oeste, e quando observado todos os anos da série histórica, o valor contratado apenas no Oeste do Estado ultrapassou os R 19 bilhões.

A região do Vale do Itajaí se posicionou na sequência em termos de volume contratado, registrando no período a quantia de $\$ 4,6$ bilhões, o que significou 13,6\% em relação ao total. A região Sul foi a terceira região que mais contratou no período (1996-2016), com um volume de $\$ 3,4$ bilhões correspondendo a $10,0 \%$ do total. Os volumes de recursos contratados pelas demais regiões estão contidos na Tabela 3.

Tabela 3 - Montante de recursos financeiros contratados por região em Santa Catarina, via Pronaf no período de 1996 a 2016.

\begin{tabular}{|c|c|c|c|c|c|c|c|}
\hline Ano & Litoral & Oeste & Norte & Serrana & Sul & Vale do Itajaí & Total SC \\
\hline 1996 & 9.329 .736 & 312.681 .823 & 28.178 .168 & 15.163 .344 & 84.849 .412 & 45.378 .738 & 495.581 .221 \\
\hline 1997 & 21.813 .116 & 389.641 .785 & 74.564 .339 & 39.269 .995 & 126.494 .741 & 140.949 .185 & 792.733 .161 \\
\hline 1998 & 23.207.049 & 301.610 .139 & 78.335 .272 & 50.983 .178 & 137.625 .944 & 132.887 .509 & 724.649 .091 \\
\hline 1999 & 27.272 .834 & 368.965 .314 & 105.538 .904 & 60.818 .436 & 132.467 .858 & 125.807 .122 & 820.870 .468 \\
\hline 2000 & 33.651 .300 & 386.385 .202 & 118.301 .902 & 60.496 .580 & 145.412 .519 & 147.782 .618 & 892.030 .120 \\
\hline 2001 & 35.115 .019 & 415.582 .463 & 107.171 .393 & 52.252 .472 & 134.339.204 & 136.818 .302 & 881.278 .853 \\
\hline 2002 & 29.154 .576 & 456.884 .012 & 72.109 .654 & 47.732 .181 & 76.835 .598 & 93.704 .933 & 776.420 .954 \\
\hline 2003 & 32.803 .792 & 499.093 .486 & 72.665 .644 & 59.239 .707 & 60.826 .629 & 100.662 .797 & 825.292 .055 \\
\hline 2004 & 45.711 .347 & 479.782 .984 & 86.105 .316 & 65.912 .727 & 79.649 .809 & 114.044 .097 & 871.206 .280 \\
\hline 2005 & 53.678 .024 & 627.819 .628 & 87.252 .957 & 80.518 .298 & 124.211 .291 & 133.291 .900 & 1.106 .772 .097 \\
\hline 2006 & 63.876 .342 & 630.364 .691 & 95.521 .818 & 101.822 .314 & 152.611 .942 & 168.235 .383 & 1.212 .432 .490 \\
\hline 2007 & 70.242 .349 & 721.858 .939 & 116.399 .447 & 123.370 .610 & 142.718 .063 & 191.476 .077 & 1.366 .065 .485 \\
\hline 2008 & 87.851 .250 & 992.449 .206 & 158.013 .260 & 159.047 .288 & 176.576 .408 & 248.982 .252 & 1.822 .919 .664 \\
\hline 2009 & 91.633 .998 & 1.411 .899 .776 & 188.549 .881 & 208.150 .645 & 202.949 .287 & 310.699 .269 & 2.413 .882 .856 \\
\hline 2010 & 141.725 .885 & 1.335 .865 .968 & 197.995.771 & 174.111 .543 & 237.282 .870 & 347.232 .054 & 2.434.214.091 \\
\hline 2011 & 130.630 .123 & 1.495 .366 .499 & 180.235 .894 & 193.944 .471 & 167.403 .093 & 303.101 .116 & 2.470 .681 .197 \\
\hline 2012 & 101.153 .648 & 1.616 .833 .573 & 183.378.082 & 220.610 .743 & 206.931 .816 & 328.650 .378 & 2.657.558.241 \\
\hline 2013 & 127.115 .226 & 1.809 .451 .948 & 226.106.263 & 253.373.754 & 242.659.091 & 397.334 .886 & 3.056 .041 .168 \\
\hline 2014 & 152.939.982 & 1.928 .830 .617 & 294.627.327 & 295.139 .847 & 335.882 .111 & 440.998 .415 & 3.448.418.299 \\
\hline 2015 & 99.275 .999 & 1.451 .461 .127 & 186.284 .763 & 225.697 .904 & 221.292.986 & 350.238 .637 & 2.534.251.416 \\
\hline 2016 & 103.781 .844 & 1.537.398.571 & 218.961 .648 & 243.313.912 & 246.667 .894 & 414.815 .040 & 2.764.938.908 \\
\hline Total & 1.481 .963 .439 & 19.170 .227 .750 & 2.876.297.701 & 2.730.969.949 & 3.435 .688 .567 & 4.673.090.709 & 34.368 .238 .115 \\
\hline
\end{tabular}

Fonte: Elaboração do autor com base em dados do Banco Central do Brasil (2016).

- Valores deflacionados para o ano de 2016 pelo INPC.

No que se refere à distribuição entre os municípios, as 295 cidades do Estado foram classificadas em quatro grupos a partir do volume de recursos contratados no período 19962016: i) os dez municípios que mais contrataram Pronaf; ii) os trinta municípios que mais acessaram recursos pelo programa; iii) os trinta municípios que obtiveram a menor contratação; iv) e, dos 235 municípios, os que ficaram no intervalo entre os trinta primeiros e os trinta últimos.

Os dez municípios que mais acessaram crédito Pronaf totalizaram no período aproximadamente R\$ 5,6 bilhões, representando 16,3\% do total. Entre estes figuraram oito municípios pertencentes à região Oeste, um da região do Litoral e outro da região do Vale do 
Itajaí. Os trinta municípios que mais acessaram recursos do programa juntos totalizaram 35,5\% do total, representando R \$12,2 bilhões de reais no período 1996-2016.

O grupo formado pelos trinta municípios que menos acessaram o crédito Pronaf representou apenas $0,7 \%$ do total. Este grupo é formado exclusivamente por municípios litorâneos de Norte a Sul do Estado, no qual não possuem base econômica centrada na agricultura. E o grupo central, composto por municípios que não ocupam as extremidades, representou $63,8 \%$ do total de crédito contratado no Estado.

Estas estatísticas demonstram disparidades entre municípios e entre as regiões do Estado, sendo que essa condição se associa a estrutura, potencial e características da agricultura familiar de cada localidade e/ou região. Entretanto, o Pronaf enquanto política pública possui a atribuição de apoio e fortalecimento, sendo assim o programa necessita de melhorias constantes visando atender todo o conjunto de agricultores familiares

\section{Considerações finais}

Conforme descrevemos ao longo deste trabalho, o rural brasileiro desempenhou (e desempenha) um papel importante nos processos de desenvolvimento econômico social do país. O modelo exportador possibilitou por um lado o impulso econômico e a geração de saldos financeiros ao país, especialmente pelo modelo de substituições de importações. Por outro lado, este modelo de agricultura concentrou a posse da terra, da renda e consequentemente a marginalização e exclusão de pequenos produtores do espaço rural. Em Santa Catarina, a predominância de propriedades de agricultura familiar evidencia a relevância dessa atividade, no volume total da produção agropecuária estadual.

Nesse cenário, o Pronaf enquanto política pública de concessão de crédito rural assume importante papel enquanto instrumento propulsor de desenvolvimento das atividades socio produtivas da agricultura familiar, na medida em que viabiliza a realização a produção. As linhas de crédito do programa possibilitam ao conjunto de agricultores familiares financiarem o custeio da produção, bem como os investimentos para ampliação e modernização de equipamentos.

A partir da implantação do Pronaf, Santa Catarina se posiciona como um dos principais contratantes dessa linha de crédito do país. Percebe-se um crescimento em volume de recursos e uma certa constante na quantidade de contratos para o acesso ao crédito Pronaf por agricultores familiares catarinenses. Esse resultado pode ser explicado pelo aumento no custo 
de produção, como também pela constituição de um processo de dependência a essa política pública. Mesmo assim, o programa representa uma forma de política pública que tem viabilizado o desenvolvimento de diferentes atividades produtivas, por meio do custeio ou investimento.

No entanto, o Pronaf representa uma entre tantas outras políticas públicas que tem fortalecido a agricultura familiar em busca de autonomia, emancipação e reprodução social, que se soma a outros programas como o Programa de Aquisição de Alimentos (PAA), Programa Nacional e Alimentação Escolar (PNAE), Seguro Agrícola e o Programa de Habitação Rural que também destinados a agricultura familiar. No período de 1996-2016, o estado de Santa Catarina apresentou crescimento significativo no que se refere ao volume de recursos, registrando crescimento superior a 550\%. Enquanto, o número de contratos apesar de também ter obtido crescimento no decorrer dos anos, teve o valor ao final da série histórica quantidade semelhante ao ano base (1996).

O crédito de custeio apresentou crescimento linear, passando o valor médio do contrato de R \$ 5 mil em 1996 para R\$ 22 mil no ano de 2016. Já o crédito para investimento, que no início do programa no estado foi praticamente nulo, com passar dos anos foi tendo seus valores incrementados, especialmente a partir do ano de 2008 com a criação da linha de crédito Mais Alimentos. A região Oeste concentrou a maior parte dos contratos e recursos, os percentuais acessados somente por esta região ultrapassaram $50 \%$ do total do Estado. Entre as demais regiões nenhuma se destacou sobre a outra, variando seus percentuais de participação até $13 \%$. Esta distribuição regional está diretamente ligada a vocação econômica e estrutura da agricultura familiar de cada região.

Cabe ressaltar que o Pronaf é uma política pública com importante papel no financiamento de atividades produtivas da agricultura familiar. Sua relevância é estratégica e observada por meio dos dados apresentados nesse estudo, reforçando a contribuição da distribuição desse recurso para as dinâmicas econômicas locais e para - pelo menos em parte reprodução da agricultura familiar, que permanece como principal forma produtiva no meio rural desse Estado.

\section{Referências}

ABRAMOVAY, Ricardo. O futuro das regiões rurais. Porto Alegre: UFRGS, 2003.

AQUINO, Joacir Rufino de; SCHNEIDER, Sergio. O Pronaf e o desenvolvimento rural brasileiro: avanços, contradições e desafios para o futuro. In: GRISA, Catia; SCHNEIDER, 
Sergio (Orgs.). Políticas Públicas de Desenvolvimento Rural no Brasil. Porto Alegre: UFRGS, 2015. p. 53-81.

BERALDO, Keile Aparecida. Dimensões do desenvolvimento rural: uma análise dos Proinf's no território bico do papagaio do Tocantins. Tese (Doutorado). Universidade Federal do Rio Grande do Sul, Programa de Pós-Graduação em Desenvolvimento Rural, Porto Alegre, 2016.

BIANCHINI, Valter. Vinte anos do PRONAF, 1995 - 2015: avanços e desafios. Brasília: SAF/MDA, 2015.

BRASIL. Decreto n. 1.946, de 28 de junho de 1996. Cria o Programa Nacional de Fortalecimento da Agricultura Familiar (Pronaf). Diário Oficial [da] República Federativa do Brasil, Brasília, DF, de 1 set. 1996.

Lei 11.326, de 24 de julho de 2006. Estabelece as diretrizes para a formulação da Política Nacional da Agricultura Familiar e Empreendimentos Familiares Rurais. Diário Oficial [da] República Federativa do Brasil, Brasília, DF, 2006.

Banco Central do Brasil. Anuário Estatístico do Crédito Rural, 1996-2016.2016. Disponível em: http://www.bcb.gov.br/ . Acesso em: 01 fev. 2017.

CARDOSO, F. H. As ideias e seu lugar: ensaios sobre as teorias do desenvolvimento. Petrópolis: Vozes, 1993.

CARDOSO, F. H.; FALETTO, E. A internacionalização do mercado: o novo caráter da dependência. In: Dependência e desenvolvimento na América Latina: ensaio de interpretação sociológica. Rio de Janeiro: Zahar Editores, 1975.

Análise integrada do desenvolvimento. In: Bielschowsky, R (Org.). Cinquenta anos de pensamento na Cepal. Rio de Janeiro: Record, 2000.

COSTA, F. A. Sete teses sobre o mundo rural brasileiro: antíteses. Revista da ABRA, edição especial, jul. 2013.

DELGADO, G. Concentração, política agrária e violência no campo: dez anos. In: SYDOW, E. S.; MENDONÇA, M. L. Direitos Humanos no Brasil 2009 - Relatório da Rede Social de Justiça e Direitos Humanos. Brasília: Rede Social de Justiça e Direitos Humanos, 15 out. 2009. p. 39-46. Disponível em: <http://www.social.org.br/dh\%20no\%20brasil\%202009.pdf>. Acesso em: 03 out. 2017.

DELGADO, Nelson Giordano. Política econômica, ajuste externo e agricultura. In: LEITE, Sérgio. Políticas públicas e agricultura no Brasil. Porto Alegre: Editora da Universidade/UFRGS, 2001.

FAVARETO, Arilson da Silva. Paradigmas do desenvolvimento rural em questão - do agrário ao territorial. Tese (Doutorado). Universidade de São Paulo, Programa de PósGraduação em Ciência Ambiental, São Paulo, 2006.

FURTADO, Celso. Cultura e Desenvolvimento em Época de Crise. Rio de Janeiro: Paz e Terra, 1984.

Análise do modelo brasileiro. 8. ed. Rio de Janeiro: Civilização Brasileira, 1986.

Terra, 2000.

Teoria e política do desenvolvimento econômico. 10. ed. Rio de São Paulo: Paz e

GAZOLLA, Marcio; SCHNEIDER, Sergio. Agricultura Familiar, Segurança Alimentar e Políticas Públicas: Uma análise a partir da produção para autoconsumo no território do Alto 
Uruguai/RS. 2004. 278f. Dissertação (Mestrado em Desenvolvimento Rural) - Universidade Federal do Rio Grande do Sul, Porto Alegre, 2004.

GRAZIANO DA SILVA, José. A modernização dolorosa : estrutura agraria fronteira agrícola e trabalhadores rurais no Brasil. Rio de Janeiro: Zahar, 1982.

. O que é questão agrária. 16. ed. São Paulo: Brasiliense, 2001.

GRISA, Catia; WESZ JUNIOR, Valdemar João; BUCHWEITZ; Vitor Duarte. Revisitando o Pronaf: velhos questionamentos, novas interpretações. RESR, Piracicaba-SP, Vol. 52, $\mathrm{N}^{\mathrm{o}} 02$, p. 323-346, Abr/Jun 2014.

GRISA, Catia; SCHNEIDER, Sergio. Três gerações de políticas públicas para agricultura familiar e formas de interação entre sociedade e Estado no Brasil. In: GRISA, Catia; SCHNEIDER, Sergio (Orgs.). Políticas Públicas de Desenvolvimento Rural no Brasil. Porto Alegre: UFRGS, 2015. p. 19-50.

GUANZIROLI, Carlos Enrique. PRONAF dez anos depois: resultados e perspectivas para o desenvolvimento rural. Revista de Economia Rural, Rio de Janeiro, v. 45, n. 2, p. 301-328, abr./jun. 2007.

IBGE. Instituto Brasileiro de Geografia e Estatística. 2017. Disponível em: <http://www.ibge.gov.br/>. Acesso em: 19 fev. 2017.

KAGEYAMA, Â. Desenvolvimento rural: conceitos e aplicações ao caso brasileiro. Porto Alegre: UFRGS, 2008.

LEITE, Sérgio. Políticas públicas e agricultura no Brasil. Porto Alegre: Editora da Universidade/UFRGS, 2001.

MARINI, R. M. Dialética da Dependência. In: TRASPADINI, R.; STEDILE, J.P. (Org.). Ruy Mauro Marini: Vida e obra. São Paulo: Expressão Popular, 2011. p. 131-185.

MARTINI, George. A trajetória da modernização agrícola: a quem beneficia?. Lua Nova Revista de cultura e política, março, 1991.

MATTEI, Lauro. Pronaf 10 anos: mapa da produção acadêmica. NEAD Estudos. Brasília: MDA, 2006.

Considerações Acerca de Teses Recentes sobre o Mundo Rural Brasileiro. RESR, Piracicaba-SP, Vol. 52, Supl. 1, p. S105-S124, 2014.

Políticas públicas de apoio à agricultura familiar: o caso recente do Pronaf no Brasil. Raízes, v.35, n.1, jan-jun /2015.

O debate sobre a reforma agrária no contexto do Brasil rural atual. Política \& Sociedade. Florianópolis, Vol. 15 - Edição Especial - 2016.

MOREIRA, Vilson Alves. Educação do campo e docência no contexto da agricultura familiar: o Programa Escola Ativa (PEA/MEC) no município de Salinas - MG. Tese (Doutorado em Desenvolvimento Rural). Universidade Federal do Rio Grande do Sul, Programa de Pós-Graduação em Desenvolvimento Rural, Porto Alegre, 2013.

RENK, Arlene Anélia; WINCKLER, Silvana. Conflitos socioambientais no oeste de Santa Catarina: desenvolvimento e (anti) ambientalismo. In: SOUZA-FRANCO, Gilza Maria; RENK, Arlene Anélia (Orgs.). Região, sociedade e ambiente. Chapecó, SC: Argos, 2013.

SCHNEIDER, S.; TARTARUGA, I. G. P. Territorio y enfoque territorial: de las referencias cognitivas a los aportes aplicados al análisis de los processos sociales rurales. In: MANZANAL, 
M.; NEIMAN, G.; LATTUADA, M. (Org.). Desarrollo rural, organizaciones, instituciones y territorio. Buenos Aires: Ciccus, 2006. p. 71-102.

SEYFERTH, Giralda. Campesinato e o Estado no Brasil. RAMBO, v. 17, n. 2, p. 395-417, 2011.

SILVA, Danielle. Produzindo Prerrogativas de Cidadania: o Acesso da Agricultura Familiar à Política de Fornecimento de Produtos para a Alimentação Escolar. Tese (Doutorado em Desenvolvimento Rural). Universidade Federal do Rio Grande do Sul, Programa de Pós-Graduação em Desenvolvimento Rural, Porto Alegre, 2015.

SORJ, Bernardo. Estado e classes sociais na agricultura brasileira. Rio de Janeiro: Zahar, 1980.

TOLEDO, Elizário Noé Boeira. O Pronaf em Salvador das Missões: Contradições de uma política de crédito. 2009. 186f. Dissertação (Mestrado em Desenvolvimento Rural) Universidade Federal do Rio Grande do Sul, Porto Alegre, 2009.

WANDERLEY, M.N.B. Raízes do campesinato brasileiro. In: TEDESCO, J.C. (Org.).

Agricultura familiar: realidades e perspectivas. 3. ed. Passo Fundo: EDIUPE. 2001.

Gênese da abordagem territorial no Brasil. In: CAVALCANTI, J. S. B.; WANDERLEY, M. N. B.; NIEDERLE, P. A. (Org.). Participação, território e cidadania: um olhar sobre a política pública de desenvolvimento territorial no Brasil. Recife: UFPE, 2014. p. 79-102.

"Franja Periférica", "Pobres do Campo", "Camponeses": dilemas da inclusão social dos pequenos agricultores familiares. In: DELGADO, Guilherme Costa; BERGAMASCO, Sonia Maria Pessoa Pereira. Agricultura Familiar Brasileira: Desafios e Perspectivas de Futuro. Brasília: Ministério do Desenvolvimento Agrário, 2017. p. 66-83.

WERLANG, Alceu Antonio. Disputas e ocupação do espaço no oeste catarinense: a atuação da Companhia Territorial Sul Brasil. Chapecó: Argos, 2006. 